\title{
ISTC - Imposto sobre serviço de transporte e de comunicação ${ }^{1}$
}

\author{
Andreza Beggiato Porto ${ }^{2}$ \\ Larissa Eleutério Silvério ${ }^{3}$ \\ Rebeca Marchezoni Alho da Silva ${ }^{4}$
}

\begin{abstract}
Resumo
0 imposto sobre serviço de comunicação está disposto na Constituição Federal em seu artigo 155, II. 0 critério material deste imposto é a prestação à terceiro, mediante contraprestação econômica, serviços de comunicação. 0 critério temporal se dá apenas com a efetiva realização dos serviços, ou seja, a ocorrência da relação comunicativa. 0 lugar em que foi efetivamente prestado o serviço de comunicação determina o critério espacial. 0 sujeito ativo deste imposto serão os Estados e o Distrito Federal, e o passivo será a pessoa (jurídica ou natural) que presta serviços onerosos de comunicação. 0 que se discute atualmente, no mundo globalizado e informatizado, é a cobrança do imposto ICMS de comunicação dos provedores de Internet e das tvs por assinatura. Tendo em vista o grande potencial econômico da Internet tal questão merece especial atenção dos legisladores e aplicadores do direito.
\end{abstract}

Palavras-Chave: Imposto; Serviço de comunicação; Comunicação; Internet;

Provedores de internet.

\section{Introdução}

O ISTC, também conhecido como ICM S sobre serviços de transporte intermunicipais ou interestaduais ou de comunicação, tem sua previsão legal no artigo 155, II da Constituição Federal, o qual dispõe que compete aos Estados e ao Distrito Federal instituir impostos sobre operações relativas à circulação de mercadorias e sobre prestações de serviços de transporte interestadual e intermunicipal e de comunicação, ainda que as operações e as prestações se iniciem no exterior.

Esta abordagem alcançará o ICM S sobre o serviço de comunicação, o qual envolve também os serviços de telecomunicação, que são espécies de comunicação.

\footnotetext{
${ }^{1}$ Trabalho apresentado como requisito parcial de conclusão da disciplina de Direito Tributário do Direito do curso de Direito da Universidade Estadual de Londrina.

${ }^{2}$ Graduanda em Direito pela Universidade Estadual de Londrina.

${ }^{3}$ Graduanda em Direito pela Universidade Estadual de Londrina.

${ }^{4}$ Graduanda em Direito pela Universidade Estadual de Londrina.
} 
A incidência deste tributo em alguns setores de telecomunicação são bastante discutidos, devendo atentar-se às exigências estabelecidas para a configuração da hipótese tributária.

\section{Regra matriz de incidência tributária nos serviços de comunicação}

O ICMS alcança os serviços de comunicação de acordo com o estabelecido na Constituição Federal em seu artigo 155, II, dispondo que compete aos Estados e ao distrito Federal instituir impostos sobre prestações de serviços de comunicação, ainda que as prestações se iniciem no exterior. Este imposto é denominado ICM S-comunicação.

Comunicação pode ser entendida como:

Comunicação (do latim communicatione) s.f. 1. Ato ou efeito de comunicar(-se). 2. Ato ou efeito de emitir, transferir e receber mensagem por meio de medo e/ou processos convencionados, quer através de linguagem falada ou escrita, quer de outros sinais, signos ou símbolos, quer de aparelhamento técnico especializado, sonoro e/ou visual [...] 11. Eng. Eletrôn. Transmissão de informação de um ponto a outro por meio de sinais sem fios, ou de ondas eletromagnéticas. 12. teor. Inf. Transmissão de mensagens entre uma fonte e uma destinação (FERREIRA apud MELO, 2004, p.65).

Há de se ressaltar que apenas os serviços de comunicação são tributáveis, e nesse sentido:

Serviço tributável é o desempenho de atividade economicamente apreciável, produtiva de utilidade para outrem, porém sem subordinação, sob regime de direito privado, com o fito de remuneração (ATALIBA apud MELO, 2004, p. 64).

\section{Hipótese tributária}

\section{Critério material}

A prestação de serviços de comunicação constitui o cerne da materialidade da hipótese de incidência tributária, compreendendo um negócio (jurídico) pertinente a uma obrigação "de fazer", de conformidade com os postulados do direito privado (MELO, 2004, p. 114). Assim, esse ICM S incide sobre o fato prestação de serviços de comunicação.

Este ICM S não alcança somente a comunicação, mas também a prestação (onerosa) do serviço de comunicação, por qualquer meio, inclusive a geração e a transmissão. "A 
comunicação só ganha relevância jurídica, para fins de ICMS, quando decorrente de um contrato oneroso de prestação de serviços" (CARRAZZA, 2003, p. 153).

A prestação a terceiro, em caráter negocial, de serviços de comunicação é a hipótese de incidência deste imposto. A onerosidade é essencial. Sendo assim, este imposto nasce do fato de uma pessoa prestar a terceiro, mediante contraprestação econômica, serviços de comunicação, ou seja, um fato apreciável em pecúnia.

Roque Antonio Carrazza (2003, p. 154) ressalta que

[...] o ICM S não incide so bre a comunicação propriamente dita, mas sobre a relação comunicativa, isto é, a atividade de alguém, em caráter negocial, fornecer a terceiros condições materiais para que a comunicação entre eles ocorra. E, depois, que, em decorrência da execução do contrato oneroso de prestação de serviços, estes efetivamente se comuniquem entre si.

Para esta incidência, faz-se necessário, portanto, a instalação de uma infraestrutura mecânica, eletrônica e técnica necessária à comunicação.

Além destes fatores, é necessário também que a comunicação se complete, pois o que é tributável não é a simples contratação do serviço. O serviço potencial de serviço de comunicação não permite tributação por meio de ICMS, este só incide a partir da concreta prestação do serviço.

Este tributo incide sobre a atividade-fim, ou seja, sobre a prestação dos serviços de comunicação, e não sobre as atividades-meio, cujos atos conduzem à uma potencial comunicação (como, por exemplo, provedores de internet) .

Desta forma, Roque Antonio Carrazza (2003, p. 156) conclui afirmando que:

Temos por indisputável, pois, que o fato imponível do ICMS em pauta ocorre não no momento em que é celebrado o contrato de prestação de serviço de comunicação, nem quando são preparados os meios mecânicos, eletrônicos e técnicos necessários à comunicação, mas, sim, quando vêm praticados os atos de execução, ou seja, quando se dá a efetiva prestação deste serviço. E esta só se dá quando pelo menos duas pessoas - diversas da que presta os serviços que possibilitam a comunicação à distância e previamente identificadas - efetivamente trocam mensagens.

A obrigação de pagar ICMS não nasce pela simples circunstância de uma pessoa comunicar-se com outra, mas sim o fato de alguém prestar a terceiro, remuneradamente, 0 serviço de comunicação. 
Se a comunicação for realizada pelo próprio prestador, ou seja, transmissão de mensagem própria, não incide o ICMS, configurando apenas um auto-serviço.

A transmissão e a mensagem transmitida não são elementos relevantes para fins deste imposto.

A divulgação de propaganda e publicidade por intermédio de out-doors, banners, painéis, alto-falantes, emissoras de rádio, emissoras de televisão, Internet, dentre outros meios, não tipifica prestação de serviço de comunicação tributável por meio de ICMS. Primeiramente, porque a empresa que realiza não coloca á disposição de terceiros os meios e modos para que troquem mensagens, ainda porque o destinatário não é identificado e por último, porque não interage com o emissor.

Os serviços de valor adicionado, os quais aumentam o valor e 0 alcance da comunicação, como por exemplo, a secretaria eletrônica, não são tributáveis por meio de ICMS. De igual forma, não são tributáveis por intermédio deste tributo, os serviços de manutenção dos equipamentos de comunicação, tributáveis, em tese, por ISS.

\section{a) Serviços de telecomunicação}

Os serviços de telecomunicação são espécie de comunicação, tendo como conceito legal (Lei 9.472/97):

\footnotetext{
"Art. 60. [...]

“§ 1‥ Telecomunicação é a transmissão, emissão ou recepção de símbolos, caracteres, sinais, escritos, imagens, sons ou informações de qualquer natureza por fio, radioeletricidade, meios óticos, ou qualquer outro el etromagnético".

"§ 20. Estação de telecomunicações é o conjunto de equipamentos ou aparelhos dispositivos e demais meios necessários à realização de telecomunicações, seus acessórios e periféricos e, quando for o caso, as instalações que os abrigam e complementam, inclusive terminais portáteis".
}

O Regulamento Geral dos Serviços de Telecomunicações (aprovado pelo Conselho Diretor da Agência Nacional de Telecomunicações-ANATEL, objeto da Resolução 73 de 25.11.98), destaca (art.3‥) que:

[...] não constituem serviços de telecomunicações, o provimento de capacidade de satélite, a atividade de habilitação ou cadastro de usuário, e de equipamento, para acesso a serviços de telecomunicações, nem os denominados serviços de valor adicionado. 
Enquanto para fins tributários a Constituição Federal exige prestação de resultado enquanto à comunicação, a lei Geral e Telecomunicações exige apenas a simples possibilidade de oferta de transmissão de sinais de qualquer natureza, independentemente de haver ou não estabelecimento de uma relação de comunicação.

Os serviços de telecomunicações trifásicos, ou seja, aqueles que envolvem as três etapas, de emissão, transmissão e recepção, constituem efetivamente serviços de comunicação, pois tem por finalidade o estabelecimento de uma relação de comunicação pessoal, individual e concreta.

b) Radiofusão - Televisão

Constata-se que a característica básica da radiofusão reside na comunicação à coletividade, de forma generalizada, com o timbre da gratuidade. Desta forma, os serviços de comunicações prestados pelas emissoras de radio e televisão, abertas ao público em geral, não encontram-se sujeitos à este tributo, uma vez que não enseja remuneração pelo tomador.

Por outro lado, o Serviço Especial por assinatura (TVA) possui elementos distintos da apontada radiodifusão, uma vez que constitui prestação de serviço especial a assinante, mediante remuneração, consiste na distribuição de sons e imagens por sinais codificados, com a utilização de canais do espectro radioelétrico.

Esta modalidade de comunicação televisiva também possui elementos distintos da radiofusão, tendo como ponto marcante a fruição de específicos e diferenciados serviços, prestados de modo oneroso a tomadores identificados, e materializados em contrato. Essas características operacionais e legais permitem vislumbrar que apenas as comunicações televisivas - por Assinatura e a Cabo - tipificam autênticos serviços de comunicação, sujeitando-se ao ISSC (CARRAZZA, 2003, p. 79).

Para Hugo de Brito Machado (apud M ELO, 2004, p. 79) incide o ICMS, pois trata-se de comunicação onerosa ou remunerada e o destinatário das mensagens é identificado.

Para Roque Antonio Carrazza (2003, p. 80) não incide o ICM S defendendo que:

[...] 0 assinante não se comunica nem com a empresa, nem com terceiros. Apenas assiste à programação. Ele, por assim dizer, adere à programação, vendo filmes, documentários, entrevistas, paridas de futebol etc., que a empresa prestadora de serviço de TV por assinatura coloca no ar. Sobremais, não participa da feitura desta mesma programação nem nela interfere. 
c) Internet

A Internet é pó nome genérico que designa o conjunto de redes, os meios de transmissão e comutação, roteadores, equipamentos e protocolos necessários à comunicação entre computadores, bem como o software e os dados contidos nestes computadores (Portaria 148, de 31.5.95, do M inistro das Comunicações) (M ELO, 2004, p. 81)

O STJ já decidiu que qualquer serviço oneroso de comunicação está sujeito ao pagamento do ICMS e, portanto, a relação entre o prestador de serviço (provedor) e 0 usuário é de natureza negocial, visando a possibilidade a comunicação desejada. Finalizou concluindo que este elemento é suficiente para constituir fato gerador de ICM S.

\section{Critério espacial}

Esse critério compreende tanto o âmbito territorial de validade da lei circunscrevendo-se aos limites geográficos dos Estados e do Distrito Federal -, como local da específica realização do fato gerador.

A Lei Complementar 87/96 procurou disciplinar a matéria na forma seguinte:

Art. 11. O local da operação ou da prestação, para os efeitos da cobrança do imposto e definição do estabelecimento responsável, é:[...]

III - tratando-se de prestação onerosa de serviço de comunicação:

a) o da prestação do serviço de radiofusão sonora e de som e imagem, assim entendido o da geração, emissão, transmissão e retransmissão, repetição, ampliação e recepção;

b) o do estabelecimento da concessionária ou da permissionária que forneça ficha, cartão, ou assemelhados com que o serviço é pago;

c) 0 do estabelecimento destinatário do serviço, na hipótese e para os efeitos do inciso XIII do art. 12;

c-1) o do estabelecimento ou domicilio do tomador do serviço, quando prestado por meio de satélite;

d) onde seja cobrado o serviço, nos demais casos;

IV - tratando-se de serviços prestados ou iniciados no exterior, o do estabelecimento ou do domicilio do destinatário.

Entende-se que o local da prestação - para o fim de determinar os sujeitos da obrigação - afeta ao ISSC - só poderá ser o lugar em que foi efetivamente prestado (realizado) o serviço de comunicação, o que torna-se intrincado precisar com segurança, pela circunstancias de as comunicações serem praticadas (recebidas e transmitidas) nos mais 
diversos pontos do território nacional, inclusive mediante a utilização de satélites, fibras óticas, ondas e cabos.

\section{Critério temporal}

O critério temporal se dá apenas com a efetiva realização dos serviços, pois a efetiva realização (conclusão ou medição por etapas) dos serviços é que ocorre a relação comunicativa, sendo fixado o aspecto temporal do tributo.

Por exemplo, a assinatura e a habilitação de linha telefônica representam atividades que não se qualificam como prestação de serviços, pois ocorrem antes da realização do próprio serviço de comunicação.

Assim, o ICM S sobre os serviços de comunicação só incide depois da concreta (real, efetiva) prestação de serviços. Serviço potencial de serviço de comunicação não permite tributação.

Para o Paraná, a lei que regula o ICM S estabelece em seu artigo 5ㅇ, VII, que se considera ocorrido o fato gerador do imposto no momento das prestações onerosas de serviços de comunicação, feitas por qualquer meio, inclusive a geração, a emissão, a recepção, a transmissão, a repetição e a ampliação da comunicação de qualquer natureza.

\section{Relação jurídica tributária}

\section{Critério subjetivo}

sujeito ativo

O ISSC (Imposto sobre Serviço de Comunicação) só pode ser criado (instituído, alterado e suprimido) pelos Estados e Distrito Federal, na qualidade de titulares da competência tributaria impositiva, conforme disposto no artigo 155, II da Constituição Federal. Entretanto, poderão ceder, ou seja, transferir sua capacidade tributária (arrecadação) a terceiros, sejam pessoas jurídicas (públicas ou privadas), ou pessoas naturais, configurando parafiscalidade.

O sujeito ativo é o Estado (ou Distrito Federal) onde o serviço de comunicação se iniciou. Ressalta-se que se o serviço começa no exterior e termina no Brasil, o ICMS comunicação cabe ao Estado (ou Distrito Federal) onde o serviço é fruído. 
sujeito passivo

O contribuinte será a pessoa (jurídica ou natural) que presta serviços onerosos de comunicação.

Para o Paraná (Lei Orgânica), a previsão legal é de que

Art. 16. Contribuinte do imposto é qualquer pessoa, física ou jurídica, que realize, com habitualidade ou em volume que caracterize intuito comercial, operações de circulação de mercadoria ou prestações de serviços de transporte interestadual ou intermunicipal e de comunicação, ainda que as operações e as prestações se iniciem no exterior.

A carga fiscal pode ser exigida de pessoa diversa da que praticou o fato gerador, dando origem à figura do responsável tributário e do substituto, da mesma forma como foi observado acima, no serviço de transporte interestadual ou intermunicipal.

Responsável tributário e substituto

Como visto, o contribuinte será a pessoa (jurídica ou natural) que presta serviços de comunicação. Entretanto, a carga fiscal pode ser exigida de pessoa diversa da que praticou 0 fato gerador. Nesse caso, observa-se a existência da responsabilidade tributária que consiste na hipótese em que a lei tributária responsabiliza outra pessoa pelo pagamento do tributo, quando não seja pago pelo sujeito passivo direto.

Pode ocorrer, também, que em certos casos a lei atribua a responsabilidade tributária a um terceiro participante do negócio jurídico, é o denominado diferimento ou substituição regressiva.

$\mathrm{Na}$ substituição progressiva o legislador indica uma pessoa responsável pelo recolhimento de um determinado valor relativamente a um fato futuro e incerto, com alocação de valor. Acontece uma antecipação de valor tributário, mediante a definição do sujeito passivo de uma obrigação não ocorrida.

No caso do Paraná, a lei estabelece que:

Art. 18. São responsáveis pelo pagamento do imposto:

$[\ldots]$

X - O contratante de serviço ou terceiro que participe de prestação de serviços de transporte interestadual ou intermunicipal e de comunicação. 
$\S 1$ 을 adoção do regime de substituição tributária será efetivada através de Decreto do Poder Executivo, sendo que em relação às operações interestaduais dependerá de acordo específico celebrado pelas unidades federadas interessadas.

Critério objetivo

Base de cálculo

A base de cálculo é o preço do serviço de comunicação, uma vez que este tributo não incide sobre serviços gratuitos, demandando sempre onerosidade, reveladora da capacidade contributiva.

Alíquota

Como visto, a alíquota é um percentual da base de cálculo. A alíquota, no Paraná, definida pela lei que dispõe sobre o ICM S, para os serviços de comunicações é de $18 \%$, de acordo com 0 artigo 14, IV, combinado com 0 § 10 do mesmo artigo.

\section{Lançamento}

0 lançamento é ato administrativo vinculado, uma vez que o agente fiscal deve conter-se às normas vigentes (princípio da estrita legalidade).

O ICMS, de modo geral, é tributo com lançamento por homologação, já que a Fazenda Pública pode cobrá-lo desde seu nascimento, sem a necessidade de realizar ato administrativo para apurar o valor a ser pago.

Assim, ocorrendo o fato gerador, o contribuinte deve imediatamente efetuar 0 pagamento da obrigação tributária. A Fazenda Pública homologará o lançamento realizado pelo particular.

O ICMS, portanto, não precisa da celebração de ato administrativo para ser exigido. Caso a Fazenda Pública tome ciência de que ocorreu fato gerador da hipótese tributária e que o particular não cumpriu sua obrigação, poderá realizar o lançamento de ofício. Constatado o inadimplemento do contribuinte, pode-se lavrar termo de infração ratificando os tributos que já deveriam ter sido satisfeitos, acrescentados das penalidades cabíveis. 


\section{Deveres instrumentais}

Os deveres instrumentais tributários são relações jurídicas, de conteúdo não patrimonial, que tem por objeto um fazer, um não-fazer, ou um suportar, sempre no interesse da administração tributária. Tais deveres só podem ser criados por meio de lei, editada pela pessoa política tributante, e visam a controlar a correta arrecadação dos tributos, o que quer dizer assegurar o perfeito cumprimento das obrigações consistentes na entrega de dinheiro ao Fisco. Ainda, tem por escopo assegurar, quando é o caso, a plena e regular fruição das isenções tributárias.

0 contribuinte do imposto em estudo, vê-se compelido pela lei aos seguintes deveres instrumentais: a) expedir nota fiscal, pela qual documenta-se a operação o prestação realizada ou, facilitando a exata cobrança do tributo; b) não obstar a atividade fiscalizatória dos agentes fazendários; e c) manter os livros fiscais e escritura-los adequadamente.

Assim, consistem em atribuições de deveres aos administrados (contribuintes, responsáveis), relativos à emissão de notas fiscais, escrituração de livros, prestações de informações, e não causar embaraço à fiscalização, com o objetivo fundamental de serem registrados e documentados os fatos que tenham, ou possam ter, implicação tributária.

A legislação ordinária (de cada Estado) deve relacionar todas as espécies de obrigações, bem como estabelecer as penalidades decorrentes do se descumprimento. A Lei paranaense que regula o ICM Sestatui que:

Art. 45. Constitui obrigação acessória qualquer situação que, na forma da legislação tributária do ICMS, impõe a prática ou a abstenção de ato que não configure obrigação principal.

$\S 1$ Incumbe ao Poder Executivo implementar as normas fixadas em convênio ou ajuste, celebrados entre a União, os Estados e o Distrito Federal, relativas ao Sistema Nacional Integrado de Informações Econômico-Fiscais (SINIEF).

$\S 200$ registro das operações de cada estabelecimento será feito através de livros, guias e documentos fiscais, cujos modelos, forma e prazos de escrituração serão estabelecidos em decreto do Poder Executivo.

§ 3o Constituem instrumentos auxiliares de fiscalização os documentos, livros e demais elementos de contabilidade em geral dos contribuintes ou responsáveis do ICMS.

§ 4으 Os elementos necessários à informação e apuração do tributo serão declarados na forma e prazo estabelecidos em decreto do Poder Executivo.

$\S 5$ o Sem prévia autorização do fisco, os livros fiscais não poderão ser retirados do estabelecimento, salvo a permanência destes em escritório especializado de contabilidade mediante comunicação à repartição fiscal de seu domićlio tributário. 
Art. 46. As pessoas físicas ou jurídicas, contribuintes ou não, responsáveis, na forma da legislação, estão obrigadas ao cumprimento das obrigações tributárias acessórias, estabelecidas através de decreto do Poder Executivo.

\section{Serviços de comunicação - incidência de ICMS sobre provedores de internet}

0 provedor de Internet (ou provedores de acesso), possibilitam a ligação com 0 mundo virtual, cuja atividade que será ou não caracterizada como prestação de serviço de comunicação, tributável pelo ICM S ou ISS, sem precisa tipificação penal.

Existem duas correntes a respeito. A primeira de incidência do ICMS afirma que 0 serviço prestado pelo provedor, ainda que não igual ao da telefonia, mas atua como meio necessário para acesso à comunicação. Observa-se os seguintes doutrinadores:

O serviço prestado pelo provedor de acesso é diferente do serviço prestado pela empresa de telefonia, pois a conexão à internet permite uma multiplicidade de conexões e uma multiplicidade de caminhos para a transmissão de mensagens. Sob este ângulo, o provedor de acesso atua como um instrumento, ou meio, para que 0 usuário possa ter acesso a um sistema de transferência de mensagens com tal flexibilidade. No âmbito da internet, só haverá transmissão de mensagem se houver um endereço lógico de origem e de destino e este endereço não é fornecido ao usuario pela empresa de telefonia. Portanto, o provedor fornece "algo mais" do que o viabilizado pela telefonia e algo mais que se insere como um meio diferenciado de realização de transmissão de mensagens (FERREIRA SOBRINHO apud MELO, 2004, p. 130).

Ainda, como explica Julio M aria de Oliveira (apud M ELO, 2004, p. 130-131):

0 serviço de acesso prestado pelo provedor não se restringe apenas a um agilizar, facilitar, maximizar a atividade comunicativa entre duas partes, mas efetivamente promover a comunicação. 0 serviço de comunicação prestado pelo provedor ao seu cliente se assemelha ao exemplo da transportadora, que continua prestando serviço de transporte a seu cliente, ainda que não o faça pessoalmente durante todo o itinerário. É de se conclui, portanto, que se diversas pessoas compõem o tier comunicacional para transmitir a mensagem em alguma etapa definida do processo, tais pessoas prestam serviços de comunicação.

A corrente que defende a não incidência do ICM S explica que:

[...] os provedores de acesso à Internet não configuram o 'canal' realizador da comunicação; não colocam à disposição do usuário os meios e modos necessários à transmissão e recepção de mensagens. Sua tarefa, por conseguinte, não é prestar serviço de comunicação, mas tornar mais eficiente o serviço comuncacional prestado por outra empresa. É simplesmente um serviço de valor adicionado, ou 
seja, serviço agregado a outro serviço, este sim de comunicação. Não pode, por tais motivos, ser objeto de tributação pelo ICM S (CARVALHO apud MELO, 2004, p. 129).

Sobre o assunto, ainda ensina Jose Wilson Ferreira Sobrinho (apud MELO, 2004, p. 129-130):

0 provedor de acesso realiza uma liberação do espaço virtual, para possibilitar, então, a comunicação entre duas pessoas. Embora seja a chave que destranca a porta da Internet, não é realidade virtual, sendo incabível a incidência do ICM S.

Para essa corrente, portanto, o provimento de acesso à Internet não pode ser considerado como uma prestação de serviço de comunicação, fugindo à competência dos Estados e Distrito Federal para instituir imposto sobre prestação de serviços de comunicação que incida sobre ele.

O STJ proferiu as seguintes decisões divergentes:

TRIBUTÁRIO. PROVEDOR DE INTERNET. Prestação de Serviço de Comunicação. Espécie de Serviço de Telecomunicações. Relação de Natureza Negocial com 0 Usuário. Fato Gerador de ICMS determinado. Incidência. Lei Complementar no 87/1996. Lei no 9.472/ 1997.

(...)

2. 0 provedor da Internet é um agente interveniente prestador de serviços de comunicação definindo-o como sendo "aquele que presta, ao usuário, um serviço de natureza vária, seja franqueando o endereço na Internet, seja armazenando e disponibilizando o site para a rede, seja prestando e coletando informações etc. É designado, tecnicamente de Provedor de Serviços de Conexão à Internet (PSC), sendo a entidade que presta o serviço de conexão à Internet (SCl).

0 provedor vinculado à Internet tem por finalidade essencial efetuar um serviço que envolve processo de comunicação exigido pelo cliente, para deter meios e técnicas que permitem 0 alcance dessa situação fática.

3. O serviço prestado pelos provedores esta enquadrado como sendo de comunicação, espécie dos serviços de telecomunicações.

4. A Lei Complementar no 87, de 13/09/1996, estabelece, em seu art. 20, que incide - ICMS sobre "prestações onerosas de Serviços de Comunicação, por qualquer meio, inclusive a geração, a emissão, a recepção, a transmissão, a retransmissão, a ampliação de comunicação de qualquer natureza'", círculo que abrange os serviços prestados por provedores ligados à Internet, quando os comercializam.

5. Qualquer serviço oneroso de comunicação está sujeito ao pagamento do ICMS.

6. A relação entre o prestador de serviços (provedor) e o usuário é de natureza negocial visando a possibilitar a comunicação desejada. É suficiente para constituir fato gerador de ICMS.

7. 0 serviço prestado pelo provedor pela via da Internet não é serviço de valor adicionado, conforme 0 define 0 art. 61, da Lei no 9.472, de 16/07/1997.

8. Recurso Provido. (REsp.no 323.358-PR - 1a Turma. Rel. Min. José Delgado - j. 21.6.2001. DJU de 3.9.2001).

TRIBUTÁRIO - ICMS - Serviços Prestados pelos Provedores de Internet - Lei 9.472/97. 
1. Os serviços prestados pelos provedores de acesso à Internet, embora considerados pelo Confaz como serviços de telecomunicações, pela definição dada no art. 60 da Lei 9.472/97, que dispôs sobre a organização dos serviços de telecomunicações, não pode ser assim classificado.

2. O serviço desenvolvido pelos provedores da Internet é serviço de valor adicionado (art. 61, Lei 9.472/97), o qual exclui expressamente da classificação de

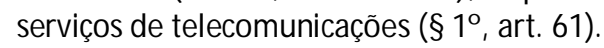

3. Se o ICMS só incide sobre serviços de telecomunicações, nos termos do art. 2ำ da LC 87/96, não sendo os serviços prestados pela Internet serviço de telecomunicações, e sim serviço de valor adicionado (art. 61, §1o da Lei 9.472/97), não há incidência da exação questionada. (ST] - REsp. 456.650-PR - Rel. Min. Eliana Calmon - 2a Turma - j. 24.6.2003. DJU 1 de 8.9.2003).

Considerando tratar-se de matéria constitucional, o STF provavelmente deverá solucionar a questão de forma definitiva.

\section{Conclusão}

A comunicação gerará relevância no universo jurídico para fins tributáveis quando decorrente de contrato oneroso de prestação de serviços. Esta atividade deverá atingir a finalidade de comunicação, não sendo suficiente 0 simples serviço potencial de comunicação. Além desses fatores, a obrigação de pagar ICMS não nasce pela simples circunstância de uma pessoa comunicar-se com outra, mas sim o fato de alguém prestar a terceiro, remuneradamente, o serviço de comunicação.

A Constituição Federal, para fins tributários, exige prestação de resultado quanto à comunicação, enquanto a lei Geral de Telecomunicações exige apenas a simples possibilidade de oferta de transmissão de sinais de qualquer natureza, independentemente de haver ou não estabelecimento de uma relação de comunicação.

Em relação ao Serviço Especial por assinatura (TVA) há posicionamentos divergentes quanto a incidência ou não do referido tributo. Este serviço de telecomunicação possui elementos distintos da radiodifusão, uma vez que constitui prestação de serviço especial a assinante, mediante remuneração, consiste na distribuição de sons e imagens por sinais codificados, com a utilização de canais do espectro radioelétrico.

Para Hugo de Brito Machado (MACHADO apud MELO, 2004. p.79) incide o ICMS, pois trata-se de comunicação onerosa ou remunerada e o destinatário das mensagens é identificado. 
Para Roque Antonio Carrazza (2003, p. 80) não incide o ICM S, sob o argumento de que não há comunicação entre 0 assinante e a empresa. Afirma que 0 assinante apenas assiste à programação, não participa da feitura desta mesma programação e nem nela interfere.

A Internet é mais uma espécie de telecomunicação discutível sobre a incidência ou não do ICMS. O STJ já decidiu que qualquer serviço oneroso de comunicação está sujeito ao pagamento do ICMS e, portanto, a relação entre o prestador de serviço (provedor) e o usuário é de natureza negocial, visando a possibilidade a comunicação desejada. Finalizou concluindo que este elemento é suficiente para constituir fato gerador de ICM S.

0 que importa ressaltar é que, no mundo atual, em que a comunicação sustenta e movimenta as principais negociações, as tvs por assinatura e a Internet são acima de tudo um grande setor de desenvolvimento econômico e gerador de renda. Resta claro o interesse estatal em tributal os serviços dessa atividade como serviços de comunicação suscetíveis ao ICMS.

Entretanto, o que ocorre, talvez pela rápida evolução dos meios de comunicação, é o despreparo e insuficiência do ordenamento jurídico brasileiro ao legislar sobre o assunto. A cobrança de tributos, regida pelos princípios do direito tributário, quer seja a legalidade ou anterioridade, não permitem essas incertezas. Em um primeiro momento, necessário se faz uma pacificação da matéria. Essa incumbência recai, acima de tudo, nos julgados do STJ e nas atribuições do STF.

\section{Referências}

BASTOS, Celso Ribeiro. Curso de direito financeiro e tributário. 9. ed. atual. e ampl. São Paulo: Celso Bastos, 2002.

CARRAZA, Roque Antônio. ICM S. 9. ed. rev. ampl. São Paulo: Malheiros, 2003.

CARRAZZA, Roque Antonio. Curso de direito constitucional tributário. 21. ed. rev. ampl. e atual. São Paulo: M alheiros, 2005

M ACHADO, Hugo de Brito. Comentários ao Código Tributário Nacional. Artigos 1ำ a 95. São Paulo: Atlas, 2003. v. 1.

M ARTINS, Sérgio Pinto. M anual de direito tributário. 5. ed. São Paulo: Atlas, 2006. 
M ELO, José Eduardo Soares de. ICM S: teoria e prática. 7. ed. atual: São Paulo: Dialética, 2004.

M ELO, José Eduardo Soares de. Imposto sobre serviço de comunicação. 2. ed. atual. ampl. São Paulo: Malheiros, 2003.

PEREIRA FILHO, Luiz Alberto. ICM S: questões polêmicas. 2. ed. Curitiba: Juruá, 2005. 